\title{
The impact of individual ladybirds (Coccinella septempunctata, Coleoptera: Coccinellidae) on aphid colonies
}

\author{
NiCOLE MINORETTI and WOLFGANG W. WEISSER ${ }^{1 *}$ \\ Zoology Institute, University of Basel, Rheinsprung 9, 4051 Basel, Switzerland \\ ${ }^{1}$ Institute of Ecology, Friedrich-Schiller-University, Dornburger Str. 159, 07743 Jena, Germany
}

Key words. Coccinella septempunctata, Acyrthosiphon pisum, aphid, predator-prey interaction, foraging, survival

\begin{abstract}
Pea aphids (Acyrthosiphon pisum) have been reported to produce winged offspring in the presence of predatory ladybirds. These offspring may leave host plants by flight after they have developed into winged adults. The inter-generational nature of this response raises the question about the chances of survival of aphids developing in attacked colonies. We studied the behaviour of predatory ladybirds on host plants by releasing adult 7-spot ladybirds (Coccinella septempunctata) on bean plants hosting either no prey individuals or colonies of 10 or 30 pea aphids. Interactions between predator and prey were recorded until the ladybird left the plant. Ladybird patch residence time increased with the number of aphids present on a plant but beetles generally left a plant before all aphids were eaten. The time budget of the ladybirds revealed a high proportion of time not spent in feeding activities. Predation rate was about one aphid killed per $10 \mathrm{~min}$ residence time in both treatments with aphid-infested plants. Aphids that survived an attack by the predator or that were alarmed when a conspecific was attacked often emigrated from the host plant, and their number was of the same magnitude as the number of aphids killed by the predator. On average, pea aphid numbers at the end of an experiment were reduced to less than a third of the initial value. The results of the experiment show that attack by single ladybirds does on average not cause immediate extinction of small aphid colonies. The short patch residence times of on average less than two hours show that a predator individual that induces winged-offspring production in an aphid colony will not any longer be present in the colony when the induced offspring mature. To understand the adaptiveness of predator-induced wing development in pea aphids the probabilities of subsequent attacks on an aphid colony need to be investigated.
\end{abstract}

\section{INTRODUCTION}

Aphid life-cycles are complex and typically consist of several asexual generations alternating with a single sexual generation (Dixon, 1998). During the phase of asexual reproduction, aphids produce a number of different phenotypes, among which are winged (alate) and unwinged (apterous) morphs. The winged morphs are mainly responsible for dispersal and the colonisation of new plants (Dixon, 1998). In many species, the winged morphs develop in response to deteriorating conditions, i.e. when aphids are crowded or feed on plants of declining quality (Hille Ris Lambers, 1966; Dixon, 1998). Recently, it has been shown for pea aphids (Acyrthosiphon pisum Harris) that predatory ladybirds can also induce the production of winged offspring (Weisser et al., 1999; Dixon \& Agarwala, 1999). Because, in the pea aphid, an offspring's phenotype is determined before birth (Sutherland, 1969), there is a lag between the time when the winged offspring are induced and the time when the offspring have matured and can leave a plant by flight. Thus, producing winged offspring in the presence of a ladybird is an inter-generational response of the aphids and not a strategy to reduce the immediate risk of being eaten by the predator (Weisser, 2000). This raises two questions concerning the behaviour of ladybirds in aphid colonies. First, do attacking ladybirds drive aphid colonies to extinction? Obviously, producing winged offspring can only be adaptive if not all aphids in an attacked colony are killed by the predator. Second, do ladybirds stay in an aphid colony until the induced offspring have matured? If this is the case, the winged aphids that leave a plant by flight would escape from the same predator individual that also induced their phenotype.

Answers to these questions can not be easily extracted from the literature. A large number of both experimental and observational studies have shown that predators have significant effects on aphid colonies (e.g. Campbell, 1978; Frazer et al., 1981a,b; Sunderland \& Chambers, 1983; Dennis \& Wratten, 1991; Morris, 1992; Chen \& Hopper, 1997). Despite this multitude of studies, however, there is still little information available about the survival of aphid colonies in the field, and the mortality caused by individual aphid predators under natural conditions. Honěk (1985) observed foraging C. septempunctata under natural conditions and found that abiotic factors such as temperature had a great influence on ladybird activity. In general, however, experiments on predator effectiveness are done in the laboratory and do not consider the survival of aphid colonies explicitly. As a consequence, it is difficult to transfer findings from the laboratory to the field (Frazer, 1988; Hodek \& Honěk, 1996).

In this study, we investigated the foraging behaviour of adult 7-spot ladybirds on bean plants to answer the questions posed above. Aphid colony sizes were chosen to resemble those regularly observed in the field (e.g. Frazer

\footnotetext{
* Corresponding author: e-mail: Wolfgang.Weisser@uni-jena.de
} 
et al., 1981a,c) and predators were free to leave a host plant at any time. The interactions between predator and prey were quantified and the fate of the aphids in the colony was noted.

\section{MATERIAL AND METHODS}

\section{Plant and animal material}

Adults of C. septempunctata were collected in Canton Basle, Switzerland and kept in plastic boxes $(12 \mathrm{~cm}$ diameter, $20 \mathrm{~cm}$ high) ventilated through nylon netting. We used the red BP clone of pea aphid (Acyrthosiphon pisum Harris) originally collected in Bayreuth, Germany, in 1997 (Weisser et al., 1999). Aphids were reared on a dwarf form of broad bean, Vicia faba L. (variety The Sutton, Nickerson-Zwaan Ltd, Roswell, Lincolnshire LN7 6DT, England). All cultures were maintained at $20.0 \pm 2{ }^{\circ} \mathrm{C}$ under long day conditions (16L : 8D).

\section{Experimental design}

Three treatments were established: broad bean plants without aphids ("aphid-free plants"), plants infested with 10 aphids, and plants infested with 30 aphids. Aphid-free plants were included in the experiment to establish that patch residence time in our population of ladybirds does depend on the presence of their prey. The composition of the aphid colonies was chosen to resemble a colony with a stable stage structure (Stearns, 1992). The rate of increase of the BP clone is roughly 0.4 aphids/day at $20^{\circ} \mathrm{C}$ (Rauch, unpublished) from which the composition of age classes was calculated. Colonies of 10 (30) individuals consisted of 3 (9) first or second instar nymphs, 3 (8) third instar nymphs, 2 (6) fourth instar nymphs and 2 (7) adult aphids. Bean plants used in the experiment were of similar height $(13.1 \pm 0.4 \mathrm{~cm})$ and had $6.8 \pm 0.2$ leaves $(\mathrm{N}=33)$. For each trial, plants with aphids were placed outdoors on a table in front of a glasshouse and caged for one hour to allow aphids to settle. Preliminary observations showed that all aphids had settled on the plant during this time period, at similar positions as when left undisturbed for much longer time periods.

Before the recording sessions, we standardised the hunger levels of the predators. A ladybird was allowed to feed to satiation for up to $3 \mathrm{~h}$ by caging it with more than 50 aphids of different developmental stages. A beetle was considered satiated when it declined to eat a 2 nd instar nymph offered on the tip of a paint-brush and contacting the mouth parts three times consecutively. Ladybirds were subsequently starved for $24 \mathrm{~h}$.

At the start of the experiment, the cage was removed and a single beetle was released at the base of the bean plant. We audiotaped aphid and predator behaviour until the predator left the plant by walking or flying off. Each plant and each ladybird were used only once. Samples sizes were $N=13$ (aphid-free plants), $\mathrm{N}=11$ (colonies of 10 aphids), and $\mathrm{N}=9$ (colonies of 30 aphids). We did not distinguish between male and female ladybirds as it is often not easy to sex an individual. Males readily feed in aphid colonies and most studies on ladybird food consumption do not consider it necessary to distinguish between the sexes (Hodek \& Honěk, 1996). Ambient temperatures were $23.6 \pm 0.5^{\circ} \mathrm{C}(\mathrm{N}=33$, temperatures measured once at the beginning of each experiment). Honěk (1985) reported that above $15^{\circ} \mathrm{C} \mathrm{C}$. septempunctata starts walking actively and above $21^{\circ} \mathrm{C}$ the propensity to fly is increased. Thus, in our experiments, movements of ladybirds were not prevented by low temperature.

Ladybirds engaged in the following behaviours: SEARCHING continuous walking on the plant, RESTING - remaining motionless on the plant, GROOMING - cleaning the body using the mouth parts, EATING - consuming a captured prey, PLANT FEEDING feeding on plant tissue, NECTAR FEEDING - feeding on nectar released by the plant. During searching, ladybirds ENCOUNTERED aphids when some part of the predator was in contact with a prey. When encountered by a ladybird, aphids were either eaten Or ESCAPED, either by WALKING away or by DROPPING from the host plant. Aphids that showed an escape reaction when a conspecific was attacked (ALARMED aphids) were noted separatedly. HANDLING TIME is the time needed by a ladybird to consume a prey after capture.

Audiotapes were transcribed onto an event-recording program (The OBSERVER, Version 2.0, Noldus Information Technology, Wageningen, The Netherlands). For each replicate we calculated the time spent on the plant (patch residence time), the number of aphids left on the plant (final colony size), and the number of individuals dislodged, i.e. the number of aphids that had dropped off the host plant and did not return (emigrants). For aphid-infested plants, measures of predator effectiveness included the number of prey encountered over a period of 10 min (encounter rate), the number of prey eaten over a period of 10 min (predation rate), and predator capture efficiency (percentage of encountered aphids that were captured and eaten).

\section{Data analysis}

Data were analysed using SAS (version 6.12, SAS Institute 1989). All dependent variables were appropriately transformed to alleviate heteroscedasticity. Time budgets were analysed by MANOVA on log-transformed proportions (Clark \& Messina, 1998).

\section{RESULTS}

\section{Behaviour of $C$. septempuncta}

Residence time of ladybirds on plants differed between treatments $\left(\mathrm{F}_{2,33}=7.60, \mathrm{p}=0.002\right.$, Fig. 1$)$ and was higher on aphid-infested than on aphid-free plants. There was a non-significant trend for longer residence times on plants with 30 -aphid colonies than on plants with 10-aphid colonies. The time-budgets of ladybirds differed between treatments (MANOVA: $\mathrm{F}_{12 / 50}=3.03, \mathrm{p}=0.003$ ). There were no significant differences in the percentages of time spent resting $\left(\mathrm{F}_{2,33}=0.19, \mathrm{p}=0.83\right)$, plant feeding $\left(\mathrm{F}_{2,33}=1.50, \mathrm{p}=\right.$ $0.24)$ or nectar feeding $\left(\mathrm{F}_{2,33}=2.39, \mathrm{p}=0.11\right)$, but only in feeding-related activities (grooming: $\mathrm{F}_{2,33}=3.87 ; \mathrm{p}=0.03$; handling: $\left.\mathrm{F}_{2,33}=17.31 ; \mathrm{p}=0.0001\right)$. The proportion of time spent searching on plants without aphids was similar to the proportion of time spent searching on aphid-infested

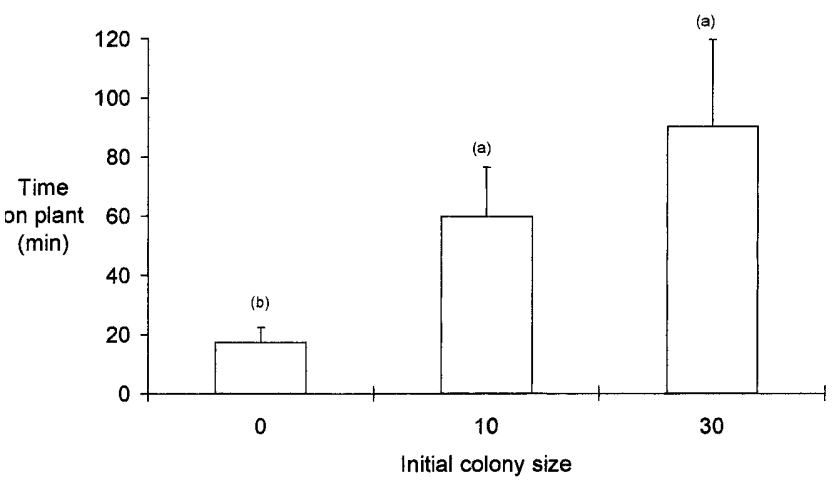

Fig. 1. Residence times on plants of $C$. septempunctata as a function of initial pea aphid colony size. Means with same letters are not significantly different from one another (HSD test after ANOVA). 
TABLE 1. Time budget of adult C. septempunctata in the experiments. Values are percentages of the total time spent on a plant (mean percentage $\pm \mathrm{SE}$ ).

\begin{tabular}{lccc}
\hline & APHID-FREE PLANT & \multicolumn{2}{c}{ APHID-INFESTED PLANT } \\
\cline { 2 - 4 } Behaviour & \multirow{2}{*}{$(\mathrm{N}=13)$} & 10-aphid colony & 30-aphid colony \\
& & $(\mathrm{N}=10)$ & $40.3 \pm 6.1$ \\
\hline Searching & $67.0 \pm 4.9$ & $63.7 \pm 6.8$ & $14.6 \pm 3.6$ \\
Grooming & $4.0 \pm 1.7$ & $9.9 \pm 3.1$ & $8.6 \pm 4.3$ \\
Resting & $12.3 \pm 5.0$ & $8.9 \pm 3.9$ & $24.0 \pm 3.4$ \\
Handling prey & 0 & $16.9 \pm 2.7$ & $0.5 \pm 0.5$ \\
Feeding on plant tissue & $5.4 \pm 2.5$ & $1.0 \pm 0.8$ & $11.1 \pm 4.9$ \\
Feeding on nectar & $5.4 \pm 3.8$ & $2.2 \pm 1.3$ & \\
\hline
\end{tabular}

plants (Table 1). Time budgets of ladybirds were generally similar in 10-aphid and 30-aphid colonies (MANOVA: $\mathrm{F}_{6 / 13,33}=2.56, \mathrm{p}=0.07$ ). The most common behaviour exhibited by ladybirds was searching, followed by eating and grooming (Table 1 ).

Ladybirds consumed on average $3.7 \pm 0.9$ aphids in colonies of 10 aphids and $5.5 \pm 1.5$ aphids in colonies of 30 aphids $\left(\mathrm{F}_{1,20}=16.83, \mathrm{p}=0.0001\right)$. In four 10 -aphids colonies and one 30-aphid colony ladybirds left the plant without eating a single aphid (Fisher's exact test: $\mathrm{p}=0.319$ ). Handling time was $2 \mathrm{~min} 32 \mathrm{~s} \pm 36 \mathrm{~s}$ for $1 \mathrm{st}-3 \mathrm{rd}$ instar nymphs and $8 \mathrm{~min} 50 \mathrm{~s} \pm 1 \mathrm{~min} 8 \mathrm{~s}$ for 4 th instar nymphs and adults $\left(\mathrm{t}_{37}=-5.373, \mathrm{p}<0.0001\right)$.

\section{Interactions between predator and prey}

On average, $58.5 \pm 7.6 \%$ of encountered aphids were killed by the beetles, and this percentage increased to $70.3 \pm 5.0 \%$ when only those ladybirds were considered that succeeded to eat at least one aphid (successful ladybirds). In the individuals that escaped, $76.2 \%$ dropped off the host plant ( $\mathrm{N}=42$ observations). Aphids that escaped an attack by walking away were often re-encountered. These individuals were then either killed or they escaped by dropping off. The number of alarmed aphids was correlated with the number of aphids encountered $\left(r_{S}=0.91\right.$, $\mathrm{p}=0.0001$ ). On average, $9.1 \pm 1.8$ alarmed aphids were observed in trials with 10-aphid colonies and $24.1 \pm 6.1$ in trials with 30 -aphid colonies $\left(\mathrm{t}_{8,10}=9.49, \mathrm{p}=0.002\right)$. Interestingly, in both 10- and 30-aphid colonies more aphids dropped off the plant without being encountered by a predator than at an encounter with a predator (colony size 10: $1.8 \pm 0.4$ after encounter by predator vs. $5.4 \pm 1.2$ without contact to a predator, $\mathrm{t}=-3.56, \mathrm{p}=0.005, \mathrm{~N}=11$; colony size $30: 2.8 \pm 0.4$ after encounter vs. $18.3 \pm 4.6$ without encounter, $\mathrm{t}=-3.72, \mathrm{p}=0.006, \mathrm{~N}=9$ ). Thus, most emigrants were probably individuals that showed an escape response without having been in direct contact with the predator.

Initial prey density did not affect encounter rate (10 aphids: $0.71 \pm 0.17$ aphids $/ 10 \mathrm{~min}, 30$ aphids: $1.1 \pm 2.9$ aphids $/ 10 \mathrm{~min}, \mathrm{~F}_{1,20}=1.52, \mathrm{p}=0.2393$ ), nor did it affect predation rate (10 aphids: $0.5 \pm 0.13$ aphids/10min, 30 aphids: $0.63 \pm 0.12, \mathrm{~F}_{1,20}=0.53, \mathrm{p}=0.48$, successful ladybirds only in both analyses).

\section{Fate of aphid colonies}

The number of aphids remaining on the plant after the ladybird had left depended on initial prey density $\left(F_{1,20}=8.85, p=0.0081\right.$, Fig. 2 ). $27.3 \%$ of 10 -aphid colo- nies and $11.1 \%$ of 30 -aphid colonies were extinct at the end of the experiment. For successful ladybirds, the proportion of colonies extinct at the end of the experiment increased to $42.8 \%$ and $12.5 \%$ of 10 -aphid and 30 aphidcolonies, respectively. The percentage of aphids that emigrated from a plant was often similar to the number of aphids killed by the predator (Fig. 3). The were no differences between 10-aphid and 30-aphid colonies in the percentages of individuals that emigrated, were eaten, or remained on the host plant (MANOVA : $\mathrm{F}_{3 / 16,20}=1.8121$, $\mathrm{p}=0.186$ ), and the analysis was marginally non-significant when only successful ladybirds were considered (MANOVA : $\mathrm{F}_{3 / 11}=3.51, \mathrm{p}=0.053$, Fig. 3 ).

\section{DISCUSSION}

In our experiments, single foraging adult ladybirds had a significant impact on the fate of pea aphid colonies. While the aphid colonies used in our experiment were not large, colonies of similar sizes are regularly observed in the field (e.g. Frazer et al., 1981a,c). In our experiment, colonies of 10 and 30 aphids were reduced to less than a third of their initial size. One interesting result is the high number of aphids dislodged through predator activity. In field situations where suitable host plants are nearby, e.g. in alfalfa fields, many of the dislodged individuals may be able to survive and colonise other plants. However, in a non-agricultural setting distances between host plants are longer and most of the dislodged aphids will die due to natural enemies (e.g. Losey \& Denno, 1998a,b), or because of abiotic causes (e.g. high ground temperature, Roitberg \& Myers, 1979). Thus, a large proportion of aphids will not survive the visit of a ladybird beetle,

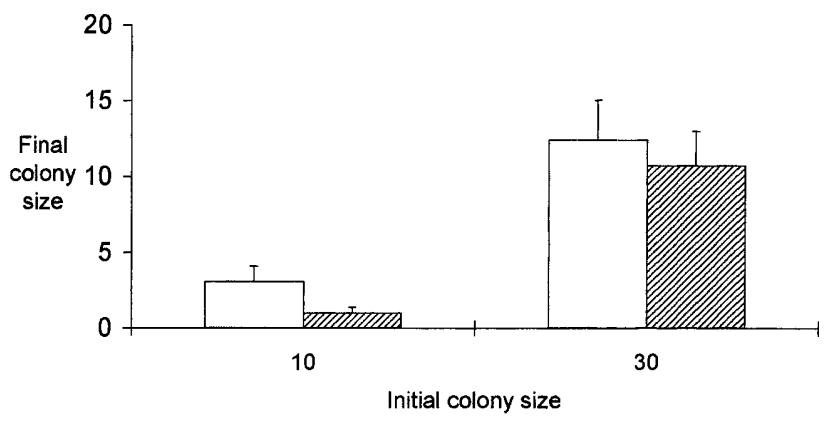

Fig. 2. The number of pea aphids remaining on the host plants at the end of the experiments as a function of initial aphid colony size. Open bars: all replicates, hatched bars: only replicates in which ladybirds killed at least one aphid (successful ladybirds) 


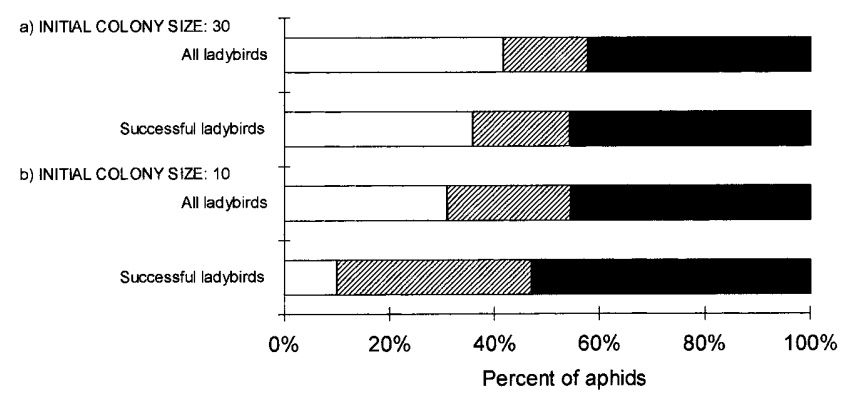

Fig. 3. Fate of aphids in the experiments depending on the initial size of the aphid colony. Aphids were eaten (hatched part of bars), emigrated from the host plant (dislodged aphid, closed part of bars) or remained on the host plant (final colony size, open part of bars). See text for explanations.

which illustrates the importance of ladybird activity for the survival of pea aphid colonies.

While ladybird impact on pea aphid colonies was considerable, the results show that attack by a single ladybird does on average not cause the extinction of an aphid colony, even when the colony is small. Different pea aphid clones may differ in susceptibility to predatory ladybirds so that the number of aphids eaten may for some clones be higher than for the clone used in the present study. With respect to the first question asked, however, the results strongly suggest that pea aphids generally have a greater-than-zero chance of survival when a predatory ladybird attacks a colony. The aphid individuals that survive may be offspring that have been determined to develop into winged morphs or may also be adult individuals which can produce further winged offspring (Weisser et al., 1999). The second question asked in this study was if ladybirds stay in an aphid colony until any of the induced winged offspring have matured. First instar offspring of the BP clone need at least seven days at $20^{\circ} \mathrm{C}$ to mature into an adult aphid (Rauch, unpubl.), which is much longer than the patch residence times of on average less than two hours observed in the experiments. Thus, the results of the present study suggest that ladybird patch residence times are generally short in comparison to the developmental time of their prey. A predatory ladybird that induces winged offspring in an aphid colony is therefore unlikely to be present in the colony when the induced offspring mature.

It is not clear how ladybirds decide when to leave an aphid colony. A detailed analysis of the reasons why $C$. septempunctata left a bean plant was beyond the scope of the present study. A number of authors have suggested that beetles decide to leave a plant when the capture rate falls below a critical value and/or when the time since the last aphid was captured exceeds a certain threshold (e.g. Frazer et al., 1981a,b; Hemptinne et al., 1992; Kindlmann \& Dixon, 1993; Dixon, 2000). Residence times on uninfested plants were quite short, supporting this view (cf. Ives, 1981).

The time budgets showed that even in warm temperatures ladybirds spent a considerable percentage of their time in activities other than feeding or searching for prey.
Grooming accounted for a significant proportion of time and was associated with feeding activities. Interestingly, ladybirds fed on plant tissues or nectar glands, presumably to obtain liquids. The resting times we observed are smaller than the ones reported by Johki et al. (1988) and Nakamuta (1983) where C. septempunctata spent about half of the time resting on the plant. Honěk (1985) showed that the proportion of individuals in four categories of behaviours (sitting or moving, on the ground or on the plant) varied with temperature, satiation (aphid abundance), sex and also over the time-course of the day. In our experiments, temperatures were high enough for ladybird activity and the beetles behaved relatively similarly within a particular treatment. Hunger level was uniform and relatively high so that beetles were motivated to search for prey. Nevertheless, the number of aphids killed per 10min-interval was independent of colony size and relatively low ( $\approx 1 \mathrm{aphid} / 10 \mathrm{~min})$. Under field conditions, Honěk (1985) reported for C. septempunctata an average predation rate of about 0.58 aphids/ 10 min for bean plants in fields where pea aphids were abundant. This is quite similar to our value. Losey and Denno (1998a) observed C. septempunctata foraging on pea aphids on alfalfa in microcosms. Predation rate was only about 0.06 aphids $/ 10 \mathrm{~min}$ and 0.11 at prey densities of 10 and 30 aphids, respectively. All these experiments differ, however, in the structure of the host plants used and complexity of the environment in which the beetles were placed. For a fuller understanding of ladybird behaviour in the field, more studies are needed in which individual beetles are observed under different conditions.

The experiments presented in this paper do not answer the question if predator-induced production of winged dispersal morphs is an adaptive strategy for pea aphids. The results make it appear unlikely that aphids produce winged offspring in the presence of a ladybird in order to allow their descendents to escape from predation by the predator individual currently foraging in the colony. On the other hand, the experiments do not allow any conclusions to be drawn about the risk of predation for aphids after a ladybird predator has attacked and left an aphid colony. For predator-induced production of winged offspring to be an adaptive strategy it has to be shown that the presence of a predatory ladybird in an aphid colony is correlated with future attacks by natural enemies on the same colony, at the time when the offspring have already matured. This can only be demonstrated in field studies.

ACKNOWLEDGEMENTS. This study was supported by the grant no $3100-053852.98$ of the Swiss Nationalfond to W. Weisser. Comments from two reviewers greatly improved the presentation of the results.

\section{REFERENCES}

CAmpbell C.A.M. 1978: Regulation of the damson-hop aphid (Phorodon humuli Schrank) on hops (Humulus lupulus L.) by predators. J. Hort. Sci. 53: 235-242.

CHEN K. \& Hopper K.R. 1997: Diuraphis noxia (Homoptera: Aphididae) population dynamics and impact of natural enemies in the Montpellier region of southern France. Envir. Entomol. 26: 866-875. 
Clark T.L. \& Messina F.J. 1998: Plant architecture and the foraging success of ladybird beetles attacking the Russian wheat aphid. Entomol. Exp. Appl. 86: 153-161.

Dennis P. \& Wratten S.D. 1991: Field manipulation of populations of individual staphylinid species in cereals and their impact on aphid populations. Ecol. Entomol. 16: 17-24.

Dixon A.F.G., 1998: Aphid Ecology. Chapman \& Hall, London, $300 \mathrm{pp}$.

Dixon A.F.G. 2000: Insect Predator-Prey Dynamics: Ladybird Beetles and Biological Control. Cambridge University Press, 264 pp.

Dixon A.F.G. \& AgaRwala B.K. 1999: Ladybird-induced lifehistory changes in aphids. Proc. R. Soc. Lond. (Series B) 266: $1549-1553$

Frazer B.D., Gilbert N., Ives P.M. \& Raworth D.A. 1981a: Predation of aphids by coccinellid larvae. Can. Entomol. 113: 1043-1046.

Frazer B.D., Gilbert N., Nealis V. \& Raworth D.A. 1981b: Control of aphid density by a complex of predators. Can. Entomol. 113: 1035-1041.

Frazer B.D., Gilbert N., Nealis V. \& Raworth D.A. 1981c: Predator reproduction and the overall predation-prey relationship. Can. Entomol. 113 : 1015-1023.

Frazer B.D. 1988: Coccinellidae. In Minks A.K. \& Harrewijn P. (eds): Aphids, their Biology, Natural Enemies and Control. Elsevier, Amsterdam, pp. 231-248.

Hemptinne J.-L., Dixon A.F.G. \& Coffin J. 1992: Attack strategy of ladybird beetles (Coleoptera : Coccinellidae): factors shaping their functional response. Oecologia 90: $238-245$.

Hille Ris Lambers D. 1966: Polymorphism in Aphididae. Annu. Rev. Entomol. 11: 47-78.

HODEK I. \& HonĚK A. 1996: Ecology of Coccinellidae. Kluwer Academic Publishers, Dordrecht, 464 pp.

HONĚK A. 1985: Activity and predation of Coccinella septempunctata adults in the field (Col. Coccinellidae). Z. Angew. Entomol. 100: 399-409.

IVES P.M. 1981: Estimation of coccinellid numbers and movement in the field. Can. Entomol. 113: 981-997.

JohKi Y., Obata S. \& Matsui M. 1988: Distribution and behaviour of five species of aphidophagous ladybirds (Coleoptera) around aphid colonies. In Niemczyk E. \& Dixon A.F.G. (eds):
Ecology and Effectiveness of Aphidophaga. SPB Acad. Publ., The Hague, pp. 35-38.

Kindlmann P. \& Dixon A.F.G. 1993: Optimal foraging in ladybird beetles (Coleoptera: Coccinellidae) and its consequences for their use in biological control. Eur. J. Entomol. $90: 443-450$.

Losey J.E. \& DenNo R.F. 1998a: Positive predator-predator interactions: enhanced predation rates and synergistic suppression of aphid populations. Ecology 70: 2143-2152.

Losey J.E. \& DENNo R.F. 1998b: The escape response of pea aphids to foliar-foraging predators: factors affecting dropping behaviour. Ecol. Entomol. 23: 53-61.

MoRRIS W.F. 1992: The effects of natural enemies, competition, and host plant water availability on an aphid population. Oecologia 90: 359-365.

Nakamuta K. 1983: Sequence of predatory behaviour of the ladybeetle Coccinella septempunctata L. (Coleoptera: Coccinellidae) on the green peach aphid, Myzus persicae Sulzer (Homoptera: Aphididae). Appl. Entomol. Zool. 18: 559-580.

RoItBerG B.D. \& MYers J.H. 1979: Behavioural and physiological adaptations of pea aphids (Homoptera: Aphididae) to high ground temperatures and predator disturbance. Can. Entomol. 111: 515-519.

SAS Institute 1989: SAS/STAT user's guide: basics. Version 6.04., SAS Institute, Cary, NC, USA.

SteARNs S.C. 1992: The Evolution of Life-Histories. Oxford University Press, Oxford, $249 \mathrm{pp}$.

SUNDERLAND K.D. \& ChAMBERs R.J. 1983: Invertebrate polyphagous predators as pest control agents: some criteria and methods. In Cavalloro R. (ed): Aphid Antagonists. Balkema A.A., Rotterdam, pp.100-108.

Sutherland O.R.W. 1969: The role of crowding in the production of winged forms by two strains of the pea aphid, Acyrthosiphon pisum. J. Insect Physiol. 15: 1385-1410.

Weisser W.W., Braendle C. \& Minoretti N. 1999: Predatorinduced morphological shift in the pea aphid. Proc. R. Soc. Lond. (Series B) 266: 1175-1182.

WeISSER W.W. 2000: Predation and the evolution of dispersal. In Reynolds D.R. \& Woiwood I. (eds): Insect Movements: Mechanisms and Consequences. CAB International, Wallingford, UK, in press.

Received January 6, 2000; accepted August 30, 2000 